\title{
Kebiasaan Sarapan di Kalangan Anak Usia Sekolah Dasar di Poliklinik Umum Departemen IImu Kesehatan Anak FKUI-RSCM
}

\section{Soepardi Soedibyo, Henry Gunawan}

Departemen Ilmu Kesehatan Anak Fakultas Kedokteran Universitas Indonesia, Rumah Sakit Dr. Cipto Mangunkusumo, Jakarta

Latar belakang. Sarapan yang tidak memadai dapat menjadi faktor yang berpengaruh pada ketidakcukupan gizi. Hasil penelitian menunjukkan sarapan memiliki dampak positif terhadap kewaspadaan, kemampuan kognitif, kualitas belajar, performa akademik, juga status nutrisi. Di Indonesia belum banyak data atau laporan mengenai pola kebiasaan sarapan di kalangan anak dan remaja usia sekolah.

Tujuan. Mengetahui pola kebiasaan sarapan di kalangan anak usia sekolah dasar.

Metode. Penelitian ini merupakan penelitian deskriptif potong lintang di Poliklinik Umum Departemen Ilmu Kesehatan Anak FKUI-RSCM periode tanggal 18- 29 Mei 2009 pada anak usia sekolah dasar beserta orangtuanya. Pengambilan sampel dilakukan secara konsekutif melalui kuesioner. Data diolah dengan SPSS 17.0.

Hasil. Dari 58 subjek penelitian, 91,4\% orangtua menganggap sarapan penting. Proporsi anak yang memiliki kebiasaan sarapan setiap hari 77,6\%, sedangkan yang memiliki kebiasaan tidak sarapan sebesar 22,4\%. Alasan yang melatar-belakangi kebiasaan sarapan sebagian besar adalah keinginan untuk membantu kecerdasan anak $(77,2 \%)$ sedangkan alasan tidak sarapan sebagian besar $(52,4 \%)$ adalah faktor selera makan anak (anak tidak mau makan). Pola menu sarapan pada subjek penelitian terutama adalah nasi dan lauk-pauk (52,6\%).

Kesimpulan. Sebagian besar orangtua menganggap sarapan penting. Proporsi anak yang biasa sarapan lebih dari tiga kali dibanding yang tidak. Kebiasaan sarapan sebagian besar adalah untuk membantu kecerdasan anak sedangkan alasan tidak sarapan sebagian besar karena anak tidak mau makan. Pola menu sarapan terutama adalah nasi dan lauk-pauk, dan secara keseluruhan adalah makanan yang kaya karbohidrat. (Sari Pediatri 2009;11(1):66-70).

Kata kunci: kebiasaan sarapan, anak usia sekolah dasar

\footnotetext{
Alamat Korespondensi:

Prof. Dr. Soepardi Soedibyo, SpA(K). Pediatri Rawat Jalan Dep. Ilmu Kesehatan Anak FKUI. Divisi Nutrisi dan Metabolik. Departemen Ilmu Kesehatan Anak FKUI-RSCM. Jl. Salemba no. 6, Jakarta 10430. Telepon: 021-3915179. Fax: 021-3907743.

Dr. Henry Gunawan PPDS Adaptasi IKA, FKUI
}

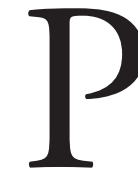
ola asupan makanan pada anak telah menjadi hal yang mendapat perhatian khusus karena pola makan pada awal kehidupan cenderung akan menetap hingga masa dewasa. ${ }^{1}$ Kebiasaan sarapan banyak mendapat perhatian pada masa anak 
dan remaja. Berbagai penelitian telah menunjukkan bahwa peniadaan atau konsumsi sarapan yang tidak memadai dapat menjadi faktor yang berpengaruh pada ketidakcukupan gizi karena kehilangan nutrisi yang ditimbulkannya jarang dapat dipenuhi oleh konsumsi makanan di waktu lain. ${ }^{2}$ Sarapan bahkan telah dianggap oleh berbagai kelompok masyarakat sebagai waktu makan paling penting dalam sehari. Kebanyakan orangtua maupun edukator cenderung menganggap sarapan sebagai prasyarat keberhasilan proses belajar selepas periode puasa yang cukup panjang pada malam sebelumnya. ${ }^{3}$ Penelitian yang ada telah memberikan fakta bahwa sarapan memang memiliki dampak yang positif baik terhadap kewaspadaan, kemampuan kognitif, kualitas belajar maupun performa akademik. ${ }^{4-7}$ Sarapan juga memberikan dampak positif pada status nutrisi. Beberapa peneliti melaporkan bahwa pola sarapan yang tidak teratur berkaitan erat dengan kejadian berat badan lebih, obesitas, serta pola perilaku yang tidak sehat. ${ }^{8-10}$

Meskipun banyak penelitian dalam kurun waktu lebih dari limapuluh tahun telah menunjukkan berbagai manfaat sarapan, namun studi observasional di banyak tempat menemukan adanya kecenderungan perilaku meniadakan sarapan di kalangan anak dan remaja. ${ }^{11}$ Di negara-negara barat dilaporkan bahwa prevalensi anak dan remaja yang tidak sarapan cukup tinggi yaitu berkisar 10\%-30\% dan terutama ditemukan pada remaja perempuan dan anak dari keluarga dengan sosial ekonomi rendah. ${ }^{11,12}$ Prevalensi sarapan juga terlihat menurun di beberapa daerah lain seperti Mesir, ${ }^{13}$ India,,${ }^{14}$ dan Srilangka, ${ }^{15}$ sedangkan di Indonesia sejauh yang penulis ketahui sampai saat ini belum banyak data atau laporan mengenai pola kebiasaan sarapan di kalangan anak dan remaja usia sekolah.

Tujuan penelitian untuk mengetahui pola pandangan orangtua anak usia sekolah dasar mengenai sarapan, mengetahui proporsi anak usia sekolah dasar yang memiliki kebiasaan sarapan dan yang tidak, mengetahui alasan-alasan yang melatar-belakangi kebiasaan sarapan dan tidak sarapan pada anak usia sekolah dasar, dan mengetahui pola jenis sarapan yang dikonsumsi anak usia sekolah dasar. Dari hasil penelitian diharapkan dapat memberikan informasi mengenai pola kebiasaan sarapan pada anak usia sekolah dasar, sehingga dapat digunakan sebagai dasar intervensi dalam meningkatkan status kesehatan maupun pendidikan dalam masyarakat.

\section{Metode}

Penelitian deskriptif potong lintang dilakukan di Poliklinik Umum Departemen Ilmu Kesehatan Anak FKUI-RSCM, pada periode tanggal 18-29 Mei 2009. Pengambilan sampel dalam penelitian dilakukan secara konsekutif melalui pengumpulan data menggunakan kuesioner. Populasi target adalah semua anak usia sekolah dasar beserta orangtuanya. Populasi terjangkau adalah semua anak usia sekolah dasar yang orangtuanya berkunjung di Poliklinik Umum Departemen Ilmu Kesehatan Anak FKUI-RSCM Analisis data dilakukan dengan menggunakan program SPSS 17.0, hasil penelitian disajikan berupa teks dan tabel dalam format laporan penelitian.

\section{Hasil}

Selama periode penelitian didapatkan 58 anak usia sekolah dasar yang orangtuanya berkunjung ke Poliklinik Umum Departemen Ilmu Kesehatan Anak FKUI-RSCM dan bersedia untuk mengisi kuesioner. Proporsi anak laki-laki dan anak perempuan yang hampir seimbang yaitu 31 (53,4\%) dan 27 (46,6\%) anak. Usia rata-rata 9 tahun, usia paling muda 6 tahun dan paling tua 13 tahun.

Dari seluruh orangtua yang menjadi responden sebagian besar berpendapat bahwa sarapan adalah sama pentingnya dengan makan di waktu yang lain $(55,2 \%)$. Tigapuluh enam persen responden mengganggap sarapan sebagai makan paling penting dalam sehari dan hanya

Tabel 1. Karakteristik anak usia sekolah dasar subjek penelitian.

\begin{tabular}{lcc}
\hline Karakteristik anak & $\begin{array}{c}\text { Jumlah } \\
\mathrm{n}=58\end{array}$ & $\begin{array}{c}\text { Persentase } \\
(\%)\end{array}$ \\
\hline Usia (tahun) & & \\
6 & 5 & 8,6 \\
7 & 6 & 10,3 \\
8 & 13 & 22,4 \\
9 & 16 & 27,6 \\
10 & 7 & 12,1 \\
11 & 2 & 3,4 \\
12 & 7 & 12,1 \\
13 & 2 & 3,4 \\
\hline Jenis kelamin & & \\
Laki-laki & 31 & 53,4 \\
Perempuan & 27 & 46,6 \\
\hline
\end{tabular}


$6,9 \%$ responden yang mengganggap sarapan tidak begitu penting. Tidak ada satupun dari responden dalam penelitian ini yang mengganggap sarapan tidak perlu.

Tabel 2. Pandangan orangtua tentang sarapan

\begin{tabular}{lcc}
\hline Pandangan tentang sarapan & $\begin{array}{c}\text { Jumlah } \\
(\mathrm{n}=58)\end{array}$ & $\begin{array}{c}\text { Persentase } \\
(\%)\end{array}$ \\
\hline Makan paling penting & 21 & 36,2 \\
Sama penting dengan makan & 32 & 55,2 \\
$\quad$ di waktu lain & & \\
Tidak begitu penting & 4 & 6,9 \\
Tidak perlu & 0 & 0,0 \\
Tidak tahu & 1 & 1,7 \\
\hline
\end{tabular}

Tabel 3. Frekuensi sarapan, alasan sarapan, dan pola menu sarapan yang dikonsumsi anak usia sekolah dasar subjek penelitian.

\begin{tabular}{lcc}
\hline & Jumlah & $\%$ \\
\hline Variabel & 9 & 15,5 \\
1-2 kali seminggu & 4 & 6,9 \\
3-4 kali seminggu & 4 & 0,0 \\
5-6 kali seminggu & 45 & 77,6 \\
Setiap hari & 0 & 0 \\
Tidak pernah sarapan & & \\
\hline Jumlah & 58 & 100,0 \\
\hline
\end{tabular}

Alasan sarapan

\begin{tabular}{lcc} 
Membantu kecerdasan anak & 44 & 77,2 \\
Agar anak tidak kurus & 2 & 3,5 \\
Anak selalu lapar di pagi hari & 0 & 0,0 \\
Anak minta sarapan & 6 & 10,5 \\
Alasan kesehatan lain & 5 & 8,8 \\
\hline Jumlah & 57 & 100,0 \\
\hline Menu sarapan & & \\
Nasi dan lauk & 30 & 52,6 \\
Roti & 13 & 22,8 \\
Bubur & 8 & 14,0 \\
Mie & 2 & 3,5 \\
Bervariasi & 4 & 7,0 \\
\hline Jumlah & 57 & 100,0 \\
\hline
\end{tabular}

Tabel 6. Alasan tidak sarapan

\begin{tabular}{lcc}
\hline Alasan & Jumlah & $\%$ \\
\hline Anak tidak mau makan & 11 & 52,4 \\
Tidak ada waktu & 7 & 33,3 \\
Takut gemuk & 0 & 0,0 \\
Tidak lapar & 3 & 14,3 \\
\hline
\end{tabular}

Sebagian besar responden pada penelitian ini mengaku memiliki kebiasaan mengkonsumsi sarapan setiap hari $(77,6 \%)$. Lima belas koma lima persen responden mengaku mengkonsumsi 1-2 kali seminggu dan 6,9\% mengkonsumsi 3-4 kali seminggu. Tidak ada satupun responden dalam penelitian ini yang menyatakan tidak pernah sarapan. Keinginan untuk membantu kecerdasan anak merupakan alasan atau motivasi terbanyak mendorong orangtua untuk memberikan sarapan $(77,2 \%)$. Sisanya memberikan sarapan karena permintaan anak $(10,5 \%)$, agar anak tidak menjadi kurus $(3,5 \%)$ dan 8,8\% responden yang lain memberikan sarapan karena alasan kesehatan lain seperti agar anak tidak sakit maag, agar anak tidak masuk angin, agar anak tidak lemas, agar stamina anak terjaga, dan agar daya tahan tubuh anak baik. Mengenai pola menu sarapan, sebagian besar responden $(52,6 \%)$ mengaku memberikan atau mengkonsumsi menu sarapan berupa nasi dengan lauk pauk, 22,8\% mengkonsumsi roti, $14 \%$ mengkonsumsi bubur, 3,5\% mengkonsumsi mie dan 7,0\% mengkonsumsi menu yang bervariasi. Duapuluh satu responden menyampaikan alasan untuk tidak memberikan atau tidak mengkonsumsi sarapan, karena anak tidak mau makan $(52,4 \%)$, tidak ada waktu, baik tidak ada waktu menyiapkan ataupun tidak ada waktu untuk makan $(33,3 \%)$, dan $14,3 \%$ karena anak tidak lapar.

\section{Diskusi}

Duapuluh dua persen anak usia sekolah dasar mempunyai kebiasaan meniadakan sarapan. Angka ini tampak sebanding dengan kisaran prevalensi yang dilaporkan peneliti sebelumnya walaupun prevalensinya sangat bervariasi. Siega-Riz $\mathrm{dkk}^{12}$ dalam survei pada kurun waktu antara 1965 sampai dengan 1991 di Amerika Serikat melaporkan adanya kecenderungan kebiasaan mengkonsumsi sarapan yang semakin menurun pada anak laki-laki dan perempuan yaitu berturut-turut $89,7 \%$ dan $84,4 \%$ di tahun 1965 menjadi $74,9 \%$ dan $64,7 \%$ di tahun 1991 . Brugman dkk $^{16}$ di tahun 1998 dalam suatu penelitian di Belanda dengan sampel 3138 mendapatkan prevalensi $5 \%$ anak sekolah dasar dan $13 \%$ anak sekolah lanjutan pertama yang meniadakan sarapan. Di Cairo, Mesir, Wahba dkk $^{13}$ tahun 2006 melaporkan prevalensi anak sekolah dasar yang meniadakan sarapan 34,9\%. Di tempat lain Senanayake $\mathrm{dkk}^{15}$ dalam survei yang dilakukan tahun 
2006/2007 pada anak usia 4-12 tahun di Srilangka mendapatkan prevalensi yang lebih besar yaitu dari 211 responden, $70 \%$ anak meniadakan sarapan sebelum mereka berangkat sekolah. Di Indonesia pada survei yang dilakukan oleh Yayasan Kusuma Buana ${ }^{17}$ tahun 2001/2002 di 13 sekolah dasar di Jakarta $(n=3495)$ mendapatkan prevalensi anak yang berangkat sekolah tanpa sarapan $16,9 \%$, sedangkan penelitian lain di Nusa Tenggara Barat ${ }^{18}$ terhadap 131 pelajar sekolah lanjutan pertama $53,44 \%$ responden mendapat sarapan sebelum berangkat sekolah, 41,89\% menyatakan kadang-kadang dan 4,58\% tidak pernah disiapkan sarapan. Perbedaan prevalensi tersebut mungkin dipengaruhi oleh banyak faktor seperti faktor perilaku, budaya maupun sosio-demografis wilayah setempat.

Peran orangtua terutama para ibu memiliki pengaruh besar dalam membentuk kebiasaan sarapan anak. Anak usia sekolah dasar memerlukan bimbingan orangtua dalam membentuk kebiasaan mereka. Sarapan pada anak usia ini memerlukan seseorang yang lebih dewasa untuk menyiapkannya dan pada umumnya adalah tugas ibu. Catatan yang menarik dalam survei oleh Senanayake dkk mendapatkan bahwa sekalipun semua ibu dari anak yang ikut serta dalam penelitian menganggap sarapan itu penting, namun tampaknya hal ini tidak diimbangi dengan sikap dan perilaku yang sesuai dengan pandangan tersebut. Kecenderungan ini tampaknya terlihat pula dalam penelitian kami. Dari $91,4 \%$ orangtua yang mengganggap bahwa sarapan sebagai hal yang penting, bahkan $36,2 \%$ di antaranya menganggap bahwa sarapan sebagai makan paling penting dalam sehari hanya $77,6 \%$ subjek yang mengaku mengkonsumsi sarapan setiap hari. Sebagian besar motivasi orangtua dalam memberikan sarapan kepada anak mereka lebih tertuju pada keinginan untuk meningkatkan kecerdasan atau kemampuan kognitif anak $(77,2 \%)$. Hanya $8,8 \%$ yang memberikan sarapan pagi dengan pertimbangan yang terkait pada kesehatan anak, sedangkan 10,5\% memberikannya berdasarkan keinginan anak. Pemahaman yang tidak memadai mengenai nilai penting sarapan, bukan saja pada aspek nilai positifnya pada fungsi kognitif tetapi juga pada status nutrisi anak mungkin saja mempengaruhi besarnya dorongan orangtua untuk membiasakan anak mereka sarapan. Apakah pengertian orangtua mengenai nilai penting sarapan ini akan dapat mempengaruhi perilaku mereka dalam mendorong kebiasaan sarapan pada anak memerlukan penelitian lebih lanjut.
Beberapa alasan yang menjadi penghalang anak untuk sarapan berkaitan dengan selera makan anak $(52,4 \%)$, tidak ada waktu menyiapkan atau makan $(33,3 \%)$, dan anak tidak lapar $(14,3 \%)$. Rohayati ${ }^{19}$ pada penelitiannya di Kudus, Jawa Tengah tahun 2003 mendapatkan beberapa faktor yang berhubungan dengan kebiasaan sarapan siswa yaitu peran ibu, tingkah laku orang terdekat, dan selera makan anak. Penelitian tersebut juga menunjukkan bahwa pelajar yang mempunyai pengetahuan yang baik tentang gizi dan kesehatan belum tentu mempunyai kebiasaan makan yang baik. Hal ini mengesankan bahwa terdapat faktor-faktor lain selain pengetahuan anak, maupun sikap dan perilaku orangtua yang dapat mempengaruhi pola kebiasaan sarapan. Kebiasaan lingkungan terdekat dalam keluarga dapat memiliki pengaruh yang bermakna pada kebiasaan sarapan anak, sehingga untuk memfasilitasi terbentuknya kebiasaan sarapan diperlukan pula intervensi bukan saja pada orang tua tetapi juga lingkungan sekitar untuk mendorong kebiasaan tersebut. Peran sekolah dalam hal ini mungkin menjadi penting dalam mempromosikan kebiasaan sarapan. Suatu contoh di Amerika Serikat sejak tahun 1966 diciptakan sebuah program sarapan sekolah secara nasional. Program tersebut tampak berhasil dalam meningkatkan asupan dan status nutrisi anak yang menjadi peserta program. Secara signifikan meningkatkan perfoma kognitif, menurunkan problem disiplin dan psikologis, mengurangi tingkat keterlambatan dan absensi, meningkatkan atensi anak dan secara umum meningkatkan suasana pembelajaran. $^{20}$

Aspek lain yang tampaknya perlu mendapat perhatian adalah komposisi menu sarapan karena hal ini akan berpengaruh pada asupan nutrien. Sampai saat ini belum ada suatu kesepakatan umum mengenai jenis makanan apakah yang seharusnya atau sebaiknya dikonsumsi untuk sarapan. Kami mendapatkan sebagian besar menu sarapan yang dikonsumsi adalah berupa nasi dan lauk pauk $(52,6 \%)$, roti $(22,8 \%)$, bubur $(14,0 \%)$, mie $(3,5 \%)$ dan menu yang bervariasi $(7,0 \%)$. Jenis menu sarapan yang dikonsumsi di setiap daerah memang sangat bervariasi tergantung pola bahan makanan dan kebiasaan di daerah tersebut. Namun beberapa penelitian yang ada menunjukkan bahwa konsumsi sarapan berenergi tinggi ( $>25 \%$ recommended dietary allowances RDA) maupun konsumsi sereal siap saji dapat memberikan asupan vitamin dan mineral harian yang lebih tinggi dibandingkan makanan 
berenergi rendah ( $<15 \%$ RDA) maupun sedang (15$25 \%$ RDA) sehingga dapat memberikan diit yang seimbang. ${ }^{8}$ Kami memberikan gambaran kasar tentang pola menu yang biasa dikonsumsi anak, namun secara umum jenis makanan yang dikonsumsi merupakan makanan berbahan dasar karbohidrat yang tinggi energi. Apakah pola makanan tersebut sudah cukup ideal baik dari segi kuantitas maupun kualitas perlu dilakukan pengamatan lebih lanjut.

\section{Kesimpulan}

Sebagian besar orangtua subjek menganggap sarapan penting sepertiga menganggap sarapan sebagai makan paling penting dan separuh menganggap sarapan sama pentingnya dengan makan di waktu lain. Proporsi anak yang memiliki kebiasaan mengkonsumsi sarapan setiap hari cukup tinggi. Alasan yang melatar-belakangi kebiasaan sarapan sebagian besar adalah keinginan untuk membantu kecerdasan anak sedangkan alasan tidak sarapan sebagian besar karena faktor selera makan anak. Pola menu sarapan pada subjek penelitian terutama adalah nasi dan lauk-pauk secara keseluruhan adalah makanan yang kaya karbohidrat.

\section{Daftar pustaka}

1. Gifft WH, Washbon MB, Harrison GG. Nutrition behavior and change. Englewood Cliffs: Prenlichall 1972;30:219.

2. Ohlson MA, Hart BP. Influence of breakfast on total day's food intake. J. Am Diet Assoc 1965;47:282-6.

3. Pollitt E, Mathews R. Breakfast and cognition: an integrative summary. Am J Clin Nutr 1998;67:804S13 S.

4. Dickie NH, Bender AE. Breakfast and performance in school children. Br J Nutr 1982;48:483-95.

5. Cromer B, Tarnowski K, Stein A, Harton P, Thornton D. The school breakfast program and cognition in adolescents. J Dev Behav Pediatr 1990;11:295-300.

6. López I, de Andraca I, Perales C. Breakfast omission and cognitive performance of normal, wasted and stunted school-children. Eur J Clin Nutr 1993;47:533-42.

7. Chandler A, Walker S, Connolly K, GranthamMcGregor SM. School breakfast improves verbal fluency in undernourished Jamaican children. J Nutr
1995; 125:894.

8. Preziosi P, Galan P, Deheeger M, Yacoub N, Drewnowski A, Hercberg S. Breakfast type, daily nutrient intakes and vitamin and mineral status of french children, adolescents and adults. J Am Coll Nutr 1999;18:171-8 .

9. Yang RJ, Wang EK, Hsieh YS, Chen MY. Irregular breakfast eating and health status among adolescents in Taiwan. BMC Public Health 2006;6:295.

10. Rahkonen AK, Kaprio J, Rissanen A, Virkkunen M, Rose RJ. Breakfast skipping and health-compromising behaviors in adolescents and adults. Euro J Clin Nutr 2003;57:842-53.

11. Rampersaud GC, Pereira MA, Girard BL, Adams J, Metzl JD. Breakfast habits, nutritional status, body weight, and academic performance in children and adolescents. J Am Diet Assoc 2005;105:743-60.

12. Siega-Riz A, Popkin B, Carson T. Trends in breakfast consumption for children in the United States from 1965 to 1991 . Am J Clin Nutr 1998;67:748S-56S.

13. Wahba SA, Mekawy AA, Ahmed RT, Mohsen WA. Breakfast skipping and dietary adequacy of primary school children in Cairo. J App Sci Res 2006;2:51-7.

14. Chitra U, Reddy CR. The role of breakfast in nutrient intake of urban schoolchildren. Public Health Nutr 2007;10:55-8.

15. Senanayake MP, Parakramadasa HMLN. A survey of breakfast practices of 4-12 year old children. Sri Lanka. J Child Health 2008;37:112-7.

16. Brugman E, Meulmeester JF, Spee-van der Wekke A, Verloove-Vanhorick SP. Breakfast-skipping in children and young adolescents in The Netherlands. Euro J Pub Health 1998;8:325-8.

17. Anonim. Ancaman di balik jajanan anak-anak. Diunduh dari: http://cyberwoman.cbn.net.id/cbprtl/Cyberwoman/detail.a spx? $x=$ Mother + And + Babyosy $=$ Cyberwoman $|0| 0|8| 593$. Diakses tanggal 8 Juli 2009.

18. Anonim. Perhatian orang tua tentukan prestasi belajar siswa. Diunduh dari: http://www.ssffmp.or.id/suplemen/ cetak_detail.asp? mid=1 Gid=182621 హkat_id =105\%kat_ $i d 1=151$ \&kat_id2=192. Diakses tanggal 8 Juli 2009.

19. Rohayati I. Beberapa faktor yang berhubungan dengan kebiasaan sarapan dan prestasi belajar siswa SD 2 Jepang Kecamatan Mejobo Kabupaten Kudus. Diunduh dari: http://www.fkm.undip.ac.id/datalindex. php?action=46idx=514. Diakses tanggal 8 Juli 2009.

20. Kennedy E, Davis C. US department of agriculture school breakfast program. Am J Clin Nutr 1998;67 (suppl):798S-803S. 